\title{
Commentary: When the hoofbeats are a zebra
}

\author{
Michael J. Reardon, MD
}

From the Department of Cardiovascular Surgery, Houston Methodist Hospital, Houston, Tex. Disclosures: Author has nothing to disclose with regard to commercial support.

Received for publication July 30, 2019; accepted for publication July 31, 2019; available ahead of print Sept 27 , 2019.

Address for reprints: Michael J. Reardon, MD, Department of Cardiovascular Surgery, Houston Methodist Hospital, 6550 Fannin St, Suite 1401, Houston, TX 77030 (E-mail: mreardon@ houstonmethodist.org). J Thorac Cardiovasc Surg 2020;159:e271 0022-5223/ $\$ 36.00$

Copyright (C) 2019 by The American Association for Thoracic Surgery https://doi.org/10.1016/j.jtcvs.2019.07.122

In this issue of the Journal, Hui and colleagues ${ }^{1}$ present a fascinating case of a large spontaneous right atrial hematoma. A 51-year-old apparently healthy, symptom-free man had a normal chest radiograph the year before the discovery of this mass, which was apparent on a chest radiograph 1 year later. Hui and colleagues ${ }^{1}$ documented this with echocardiography as well as computerized tomography showing a large mass with partial obstruction of the superior vena caval orifice. Surgical resection was successful, and the patient made an uneventful recovery. I congratulate Hui and colleagues ${ }^{1}$ on this outcome.

This case is interesting from several perspectives. The first is that cardiac masses and tumors are uncommon and generally of interest to cardiac surgeons. About threequarters of primary cardiac tumors are benign, and of the quarter that are malignant, about three-quarters are sarcoma. ${ }^{2}$ Although primary benign tumors are more common, tumors on the right side of the heart carry an increased risk of being malignant. ${ }^{3}$ This makes differentiating benign from malignant masses even more critical for right-sided masses. How we do this is of interest to cardiac surgeons. We find cardiac magnetic resonance imaging particularly helpful, because it can establish the presence or absence of perfusion in most cases. ${ }^{4}$ A cardiac magnetic resonance imaging study in this case might or might not have shown perfusion, because hematomas have no perfusing vessels, but there did appear to be some sinuses of perfusion in the mass. If clinical information and imaging suggest that this is a potential tumor, then the treatment pathway should also be of interest to cardiac surgeons. Not all large right heart masses are best treated by surgical resection. Intracavitary clot is usually approached with anticoagulation. In this atrial wall hematoma, the likely outcome of anticoagulation is not known from the surgical literature. If this had turned out to be a tumor, surgeons would need to realize that not all right-heart tumors are best treated with resection. Large right heart tumors are not uncommonly lymphomas, which are best treated by chemotherapy alone. ${ }^{5}$ We have even seen large tumors on the right side, such as

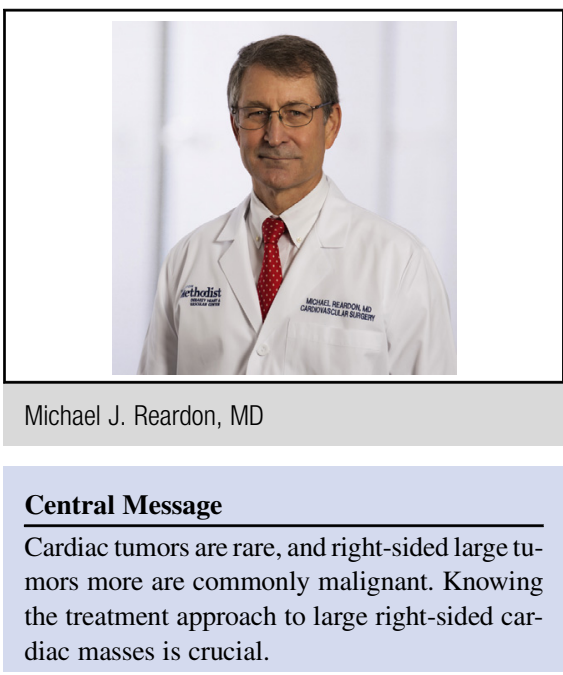

See Article page e267.

plasmacytoma, that do not require surgery. ${ }^{6}$ Another important aspect of large right-sided cardiac masses is the possibility of primary cardiac sarcoma. We have shown that with primary cardiac sarcoma, neoadjuvant chemotherapy doubled our ability to achieve R0 resection and survival. Our approach to large-right sided cardiac tumors is to get a biopsy-proven histologic diagnosis and plan therapy on the basis of this finding.

I appreciate the opportunity to read and review this interesting case report. Sometimes the hoofbeats bearing down on you are horses, but occasionally they are zebras. Surgeons need to know how to handle both. I appreciate the addition to our knowledge base by Hui and colleagues and again congratulate them on a successful outcome.

\section{References}

1. Hui C, Chen Z, Yao W, Zeng R. Spontaneous right atrial intramural hematoma J Thorac Cardiovasc Surg. 2020;159:e267-70.

2. Yanagawa B, Mazine A, Chan EY, Barker CM, Gritti M, Reul RM, et al. Surgery for tumors of the heart. Semin Thorac Cardiovasc Surg. 2018;30:385-97.

3. Bakaeen FG, Reardon MJ, Coselli JS, Miller CC, Howell JF, Lawrie GM, et al Surgical outcome in 85 patients with primary cardiac tumors. Am J Surg. 2003; 186:641-7; discussion 647.

4. Kassi M, Polsani V, Schutt RC, Wong S, Nabi F, Reardon MJ, et al. Differentiating benign from malignant cardiac tumors with cardiac magnetic resonance imaging. J Thorac Cardiovasc Surg. 2019;157:1912-22.e2.

5. Kim MP, Correa AM, Blackmon S, Quiroga-Garza G, Weilbaecher D, Bruckner B, et al. Outcomes after right-side heart sarcoma resection. Ann Thorac Surg. 2011; 91:770-6.

6. Blau LN, Reardon MJ. Surgical dilemmas: diagnosis and treatment of atrial plasmacytoma. Ann Thorac Surg. 2014;98:2226-7.

7. Abu Saleh WK, Ramlawi B, Shapira OM, Al Jabbari O, Ravi V, Benjamin R, et al. Improved outcomes with the evolution of a neoadjuvant chemotherapy approach to right heart sarcoma. Ann Thorac Surg. 2017;104:90-6. 